\title{
Shape-Controlled Synthesis of Palladium-Copper Nanoalloys with Improved Catalytic Activity for Ethanol Electrooxidation
}

\author{
Hao Wang, Weihua Yang, Qinhao Zhang, and Qingchao Qiu \\ College of Materials Science and Engineering, Huaqiao University, Xiamen 361021, China \\ Correspondence should be addressed to Weihua Yang; hzhyangwh@163.com
}

Received 6 November 2015; Revised 30 December 2015; Accepted 6 January 2016

Academic Editor: Jiujun Zhang

Copyright ( 2016 Hao Wang et al. This is an open access article distributed under the Creative Commons Attribution License, which permits unrestricted use, distribution, and reproduction in any medium, provided the original work is properly cited.

\begin{abstract}
A facile solvothermal strategy is developed for the preparation of nanometer sized Pd-Cu alloy. We can control the morphology of these alloys with the use of ethylene glycol (EG) in the presence of $\mathrm{KOH}$. Namely, by increasing the concentration of KOH/EG, the $\mathrm{Pd}-\mathrm{Cu}$ alloys with different morphologies from near-spherical nanoparticles (NPs) to nanorods and nanowire networks have been prepared. Among all these alloys, near-spherical Pd-Cu NPs-modified electrodes exhibit the highest catalytic activity $\left(11.7 \mathrm{~mA} / \mathrm{cm}^{2}\right)$ and stability toward the electrooxidation of ethanol in comparison with commercial Pd/C-modified ones $\left(2.1 \mathrm{~mA} / \mathrm{cm}^{2}\right)$.
\end{abstract}

\section{Introduction}

In recent years, fuel cells based on energy conversion have gathered increasing attraction due to their favorable efficiency, high specific energy density, and low environmental damage $[1,2]$. Among various types, direct ethanol fuel cells (DEFCs), especially operating in alkaline media, are more advantageous in practical application. Their energy supplier is the renewable resource of ethanol which is less toxic but possesses a higher theoretical energy density than methanol, and they have less complexity in cell construction [3]. However, the efficiency of DEFC is mostly determined by the catalyst deposited on the anode for ethanol oxidation reaction (EOR). Currently, noble metal nanomaterials (NMs) are widely used as catalysts in fuel cells [4-6]. Among them, Pt and Pd-based catalysts are of central significance for fuel cells [7], especially for DEFCs, owing to their preferable effectiveness for alcohol electrooxidation [8]. Compared with $\mathrm{Pt}$, Pd seems to be more attractive as catalyst, due to its low cost, relatively high abundance, comparable electroactivity, and almost no CO-poisoning effects [7, 9-11].

It has been reported that the shape, size and composition of NMs are the key factors to their catalytic activity [7, 12-15]. For instance, $\mathrm{Pd}_{x} \mathrm{Cu}_{1-x} / \mathrm{C}$ catalysts obtained in a hydrazine hydrate solution were found to be effective in EOR in alkaline medium and $\mathrm{Pd}_{0.9} \mathrm{Cu}_{0.1} / \mathrm{C}$ catalyst showed the best catalytic activity for ethanol oxidation [11]. The Pd-Cu NPs with various shapes from cubic to porous were prepared in L-ascorbic acid solution, equipping the enhanced catalytic activity for methanol oxidation [16]. Zhang and coworkers successfully fabricated the Pd-Cu tripod alloys with different compositions and controllable sizes in L-ascorbic acid system, which exhibited the superior catalytic properties for formic acid oxidation [17]. While successful, most of these Pd-Cu alloys were synthesized in an aqueous solution with the use of additional reductant; the synthesis of them in an anhydrous synthetic system through a wet chemistry technique still remains a great challenge.

In this study, we present a facile solvothermal strategy to synthesize shape-controlled bimetallic Pd-Cu alloys. Here, the EG is used as both solvent and reducing agent. To the best of our knowledge, there has been no prior work regarding the morphology-controlled synthesis of $\mathrm{Pd}-\mathrm{Cu}$ alloys through tuning the concentration of KOH/EG. In order to find out the optimal alloy, the catalytic activity of $\mathrm{Pd}-\mathrm{Cu}$ alloys was investigated for EOR, using commercial $\mathrm{Pd} / \mathrm{C}$ catalyst as references.

\section{Experimental}

2.1. Materials Synthesis. To synthesize $\mathrm{Pd}-\mathrm{Cu}$ alloys, $0.5 \mathrm{~mL}$ of $48 \mathrm{mM} \mathrm{Na}_{2} \mathrm{PdCl}_{4} / \mathrm{EG}$ and $0.1 \mathrm{~mL}$ of $240 \mathrm{mM} \mathrm{Cu}\left(\mathrm{CH}_{3} \mathrm{COO}\right)_{2}$. $\mathrm{H}_{2} \mathrm{O} / \mathrm{EG}$ were mixed together with EG (final volume $10.0 \mathrm{~mL}$ ), which contained $111 \mathrm{mg}$ polyvinylpyrrolidone (PVP, 
$\mathrm{MW}=30000), 83 \mathrm{mg} \mathrm{KI}$, and a variable concentration (1, 10 , or $100 \mathrm{mM}$ ) of $\mathrm{KOH} / \mathrm{EG}$. The mixed solution was stirred for $30 \mathrm{~min}$ at room temperature to obtain a homogeneous suspension. Then the mixture was transferred into a $20 \mathrm{~mL}$ Teflon-lined stainless steel autoclave and maintained at $200^{\circ} \mathrm{C}$ for $6 \mathrm{~h}$ in oven. The entire synthesis procedure above should be under anhydrous system. After the autoclave was cooled to room temperature naturally, the final black product was collected by centrifugation, thoroughly washed with ethanol and deionized water to remove the residual PVP and EG, and preserved in ethanol for further characterization.

2.2. Materials Characterization. A Hitachi H7650 transmission electron microscopy (TEM) was used to observe the nanoparticle shape and distribution. The nanoparticle structures and phase purity were conducted by powder Xray diffraction (XRD) spectroscopy using a Japan Rigaku $\mathrm{D} / \mathrm{max}-2500$ diffractometer equipped with $\mathrm{Cu} \mathrm{K} \alpha$ radiation $(\lambda=1.54056 \AA)$. The ratio of $\mathrm{Pd}$ and $\mathrm{Cu}$ in the as-prepared $\mathrm{Pd}-\mathrm{Cu}$ alloys was performed by X-ray energy dispersive spectroscopy (EDS). TEM analysis was operating at $200 \mathrm{kV}$, and then drops of the suspension were deposited on a copper mesh covered with carbon film for TEM observation.

2.3. Electrochemical Measurements. The electrochemical experiments in this study were performed with a conventional three-electrode electrochemical cell on a CHI 660E electrochemical workstation (CH Instruments, Chenhua Company, Shanghai, China). A platinum foil, a saturated calomel electrode (SCE), and a glassy carbon electrode (GCE, $3 \mathrm{~mm}$ in diameter) were used as the counter electrode, the reference electrode, and the working electrode, respectively. Aliquots $(14 \mu \mathrm{L})$ of the as-synthesized $\mathrm{Pd}-\mathrm{Cu}$ alloys solutions were dropped homogeneously on the clean GCE followed by casting Nafion solution (0.05 wt.\%, $5 \mu \mathrm{L})$ on the electrode surfaces to seal the samples in place and air-dried for $30 \mathrm{~min}$ at ambient temperature. Cyclic voltammetry (CV) measurements were collected to examine the electrochemical active surface area (ECSA) and the electrocatalytic activity of $\mathrm{Pd}-\mathrm{Cu}$ alloy catalysts for EOR. Chronoamperograms (CA) measurements were then employed to study the stability of these catalysts.

\section{Results and Discussion}

3.1. Characterization of $\mathrm{Pd}-\mathrm{Cu}$ Alloy Catalysts. Figure 1 displays our process and XRD patterns of resulting $\mathrm{Pd}-\mathrm{Cu}$ alloys. When the concentration of $\mathrm{KOH} / \mathrm{EG}$ was relatively low $(\sim 1 \mathrm{mM})$, that is, the theoretical $\mathrm{pH}$ value of the reaction system was 11, the near-spherical Pd-Cu NPs were obtained (Figure 1(a)). From the XRD patterns (Figure 1(b)), it can be seen that our products are very close to those of pure $\mathrm{Pd}$ (JCPDS: 87-0643). We found that the shape of as-prepared products changed from near-spherical to nanorods after increasing the concentration of $\mathrm{KOH} / \mathrm{EG}$ to $10 \mathrm{mM}$. The diffraction peaks of the nanorods shift to a higher angle, which are located between those of pure Pd and Cu (JCPDS: 65-9743), confirming the formation of Pd-Cu alloys. When the concentration of $\mathrm{KOH} / \mathrm{EG}$ was increased to $100 \mathrm{mM}$, namely, the theoretical $\mathrm{pH}$ value of the reaction solution went up to 13, the morphology of as-synthesized alloys changed to nanowire networks, and their characteristic peaks on XRD are shifted toward that of pure $\mathrm{Cu}$. Moreover, the diffraction peaks in the XRD patterns of these Pd-Cu alloys are all shifted toward higher angles with increase of the concentration of $\mathrm{KOH} / \mathrm{EG}$, which means that the proportion of $\mathrm{Cu}$ increased as more $\mathrm{KOH} / \mathrm{EG}$ was added to the synthetic system. Or in other words, the $\mathrm{KOH} / \mathrm{EG}$ with a high concentration has promoted the reduction of $\mathrm{Cu}^{2+}$. In addition, the EDS measurement shows that the corresponding molar ratio of $\mathrm{Cu}$ to $\mathrm{Pd}$ in the $\mathrm{Pd}-\mathrm{Cu}$ near-spherical, nanorods, and nanowire networks alloys is approximately 0.27, 0.93, and 1.97, respectively, which exactly agrees with the XRD data.

The as-prepared electrocatalysts were characterized using TEM analysis. Figures 2(a) and 2(b) show the as-prepared $\mathrm{Pd}-\mathrm{Cu}$ near-spherical NPs and their average size. We found that the particles are not entirely spherical; instead they had edged features and a relatively small size fluctuation $(d=56.7 \pm 5.7 \mathrm{~nm}$ ) (Figure 2(c)). The XRD pattern of near-spherical NPs (Figure 1(b)) displays that the diffraction peaks appear between the peaks for pure $\mathrm{Pd}$ and $\mathrm{Cu}$, and no characteristic peaks of $\mathrm{Cu}$ or its oxides are detected, suggesting the formation of $\mathrm{Pd}-\mathrm{Cu}$ alloys [18]. Furthermore, the amount of $\mathrm{Pd}$ is about 3.7 times higher than that of $\mathrm{Cu}$, as strongly determined by EDS data (Figure 2(d)). This may be due to much easier reduction of $\mathrm{Pd}^{2+}$ to $\mathrm{Pd}(0.92 \mathrm{~V}$ versus RHE) compared to that of $\mathrm{Cu}^{2+} / \mathrm{Cu}(0.34 \mathrm{~V}$ versus $\mathrm{RHE})$; in particular the concentration of $\mathrm{KOH} / \mathrm{EG}$ is still relatively low.

With an increase of the concentration of $\mathrm{KOH} / \mathrm{EG}$, we observed that the shape of as-prepared alloys changed from near-spherical to nanorods structures. Figures 3(a) and 3(b) show the typical TEM images of Pd-Cu nanorods. According to the TEM images, it can be seen that the synthetic products consist of most Pd-Cu nanorods (diameter, $\sim 18 \mathrm{~nm}$ ) with an aspect ratio of $\sim 6$ and few irregular $\mathrm{Pd}-\mathrm{Cu}$ NPs about $10-30 \mathrm{~nm}$ in diameter. The EDS spectrum (the inset in Figure 3(a)) shows the existence of both $\mathrm{Pd}$ and $\mathrm{Cu}$ in each of the nanorods, which can further be proven by the XRD results (Figure 1(b)).

In order to explore the effect of $\mathrm{KOH} / \mathrm{EG}$ on the morphology, we further increased the concentration of $\mathrm{KOH} / \mathrm{EG}$ while keeping all other synthetic conditions unchanged. Figures 4(a) and 4(b) show the typical TEM images of the as-prepared $\mathrm{Pd}-\mathrm{Cu}$ nanowire networks with different magnifications, revealing that the products consist of uniform nanowire networks with high yield. From the pattern of particle size distribution (Figure $4(\mathrm{c})$ ), we found that the average diameter of the $\mathrm{Pd}-\mathrm{Cu}$ alloys is about $8.34 \pm 0.6 \mathrm{~nm}$, and their length is observed to be several tens of nanometers. From the EDS spectrum (Figure $4(\mathrm{~d})$ ) and XRD results (Figure 1(b)), we can conclude that the nanowire network consisted of a $\mathrm{Pd}-\mathrm{Cu}$ alloy. In addition, the atomic ratio of $\mathrm{Pd} / \mathrm{Cu}$ is determined to be approximately $1: 2$ from the EDS data (Figure $4(\mathrm{~d})$ ). This may be due to the preferential reduction of $\mathrm{Cu}$ species in comparison with $\mathrm{Pd}$ species when the concentration of $\mathrm{KOH} / \mathrm{EG}$ is relatively high. 


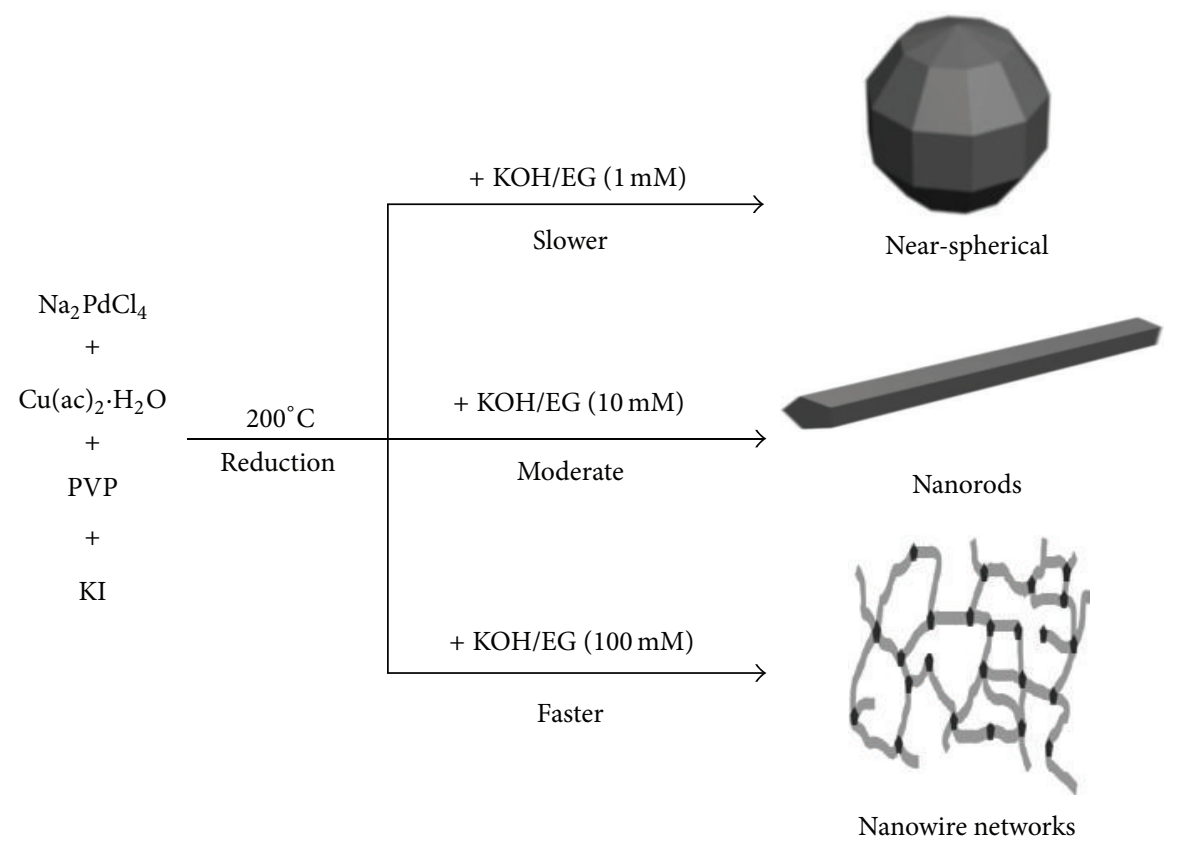

(a)

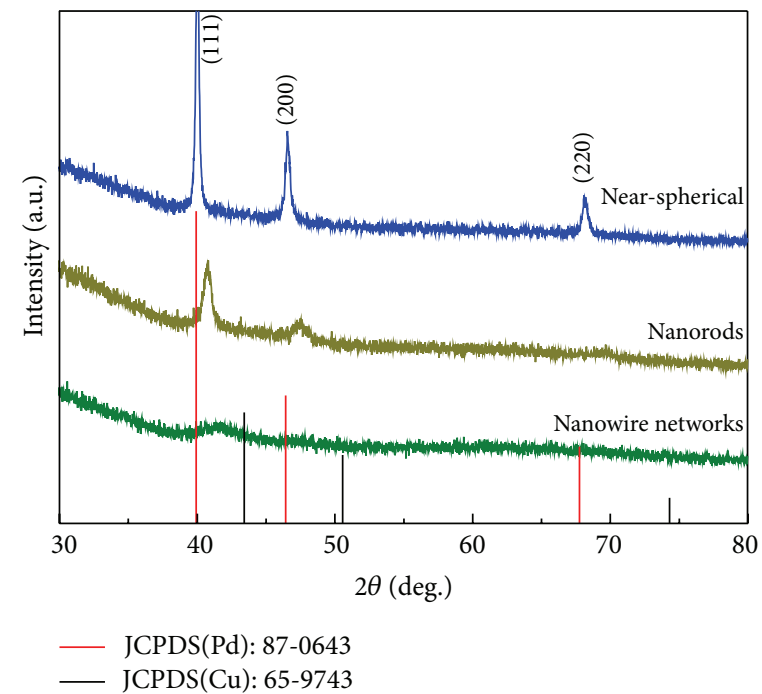

(b)

FIgURE 1: (a) Schematic illustration of the synthetic pathways leading to the formation of Pd-Cu alloys with three different structures and (b) XRD patterns for the corresponding alloys.

According to the above results, the morphology of the prepared Pd-Cu alloys can be remarkably changed by varying the concentration of $\mathrm{KOH} / \mathrm{EG}$ [18]. To explore the limit of $\mathrm{KOH} / \mathrm{EG}$, we have further carried out a series of control experiments. Figures 5(a) and 5(b) show that Pd-Cu nearspherical NPs were still obtained under the same conditions but with the lower concentration $(0.1 \mathrm{mM})$ of $\mathrm{KOH} / \mathrm{EG}$. Furthermore, as illustrated in Figures 5(c) and 5(d), the products consist of nanowire networks as usual when the concentration of $\mathrm{KOH} / \mathrm{EG}$ was further increased to $1 \mathrm{M}$. It can be thus deduced that KOH/EG mainly plays a crucial role of shape controllers in the synthesis of these Pd-Cu alloys [18]. However, further studies are still required to fully understand how $\mathrm{KOH} / \mathrm{EG}$ with different concentration determines the shape evolution of these Pd-Cu alloys.

3.2. Electrochemical Behavior of Pd-Cu Alloy Catalysts. Figure 6 plots the $\mathrm{CV}$ curves of commercial $\mathrm{Pd} / \mathrm{C}$ and $\mathrm{Pd}-\mathrm{Cu}$ alloy catalysts in $0.5 \mathrm{M} \mathrm{KOH}$ at a scan rate of $50 \mathrm{mV} / \mathrm{s}$. All the specific current density $(j)$ was normalized to the ECSA, which was estimated from the charges associated with the reduction peak of $\mathrm{PdO}$ using CV data, assuming $405 \mu \mathrm{C} / \mathrm{cm}^{2}$ for the reduction of a PdO monolayer [19]. Figure 7(a) shows the electrocatalytic activity of these catalysts toward ethanol oxidation, which was investigated in $0.5 \mathrm{M} \mathrm{KOH}$ containing $1.0 \mathrm{M}$ ethanol. It is clear that $\mathrm{Pd}-\mathrm{Cu}$ near-spherical NPs 


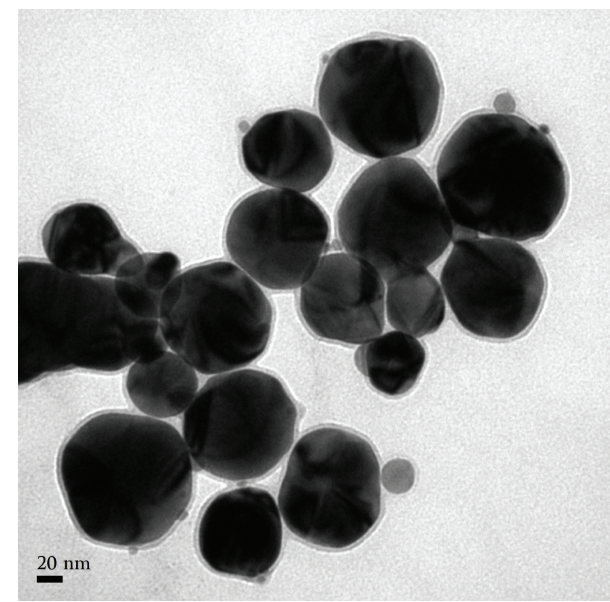

(a)

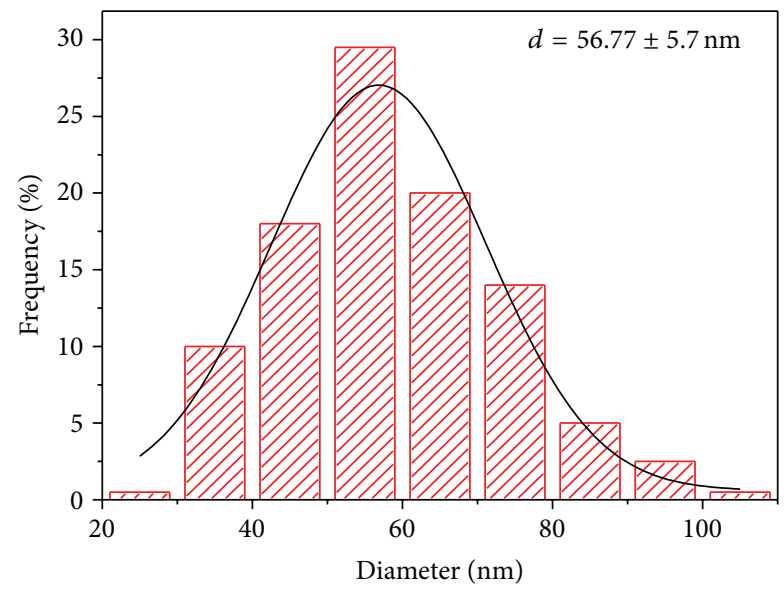

(c)

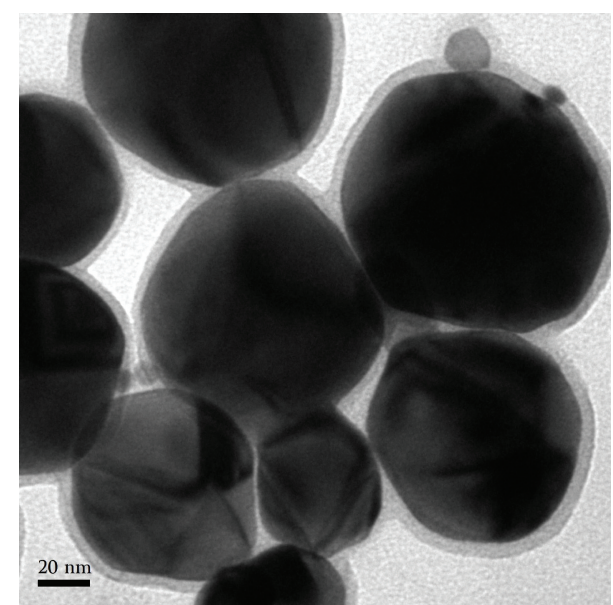

(b)

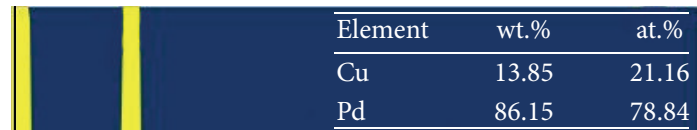

(d)

FIgure 2: (a, b) Typical TEM images of Pd-Cu near-spherical NPs with different magnifications. (c) Particle size distribution analysis. (d) EDS spectrum of the corresponding NPs.

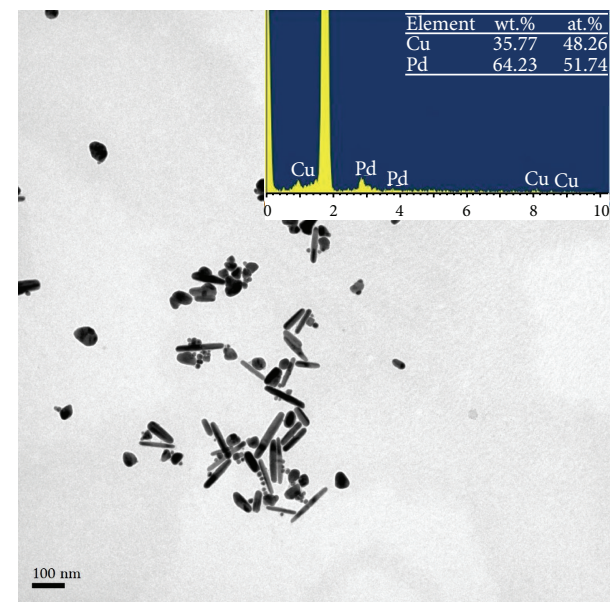

(a)

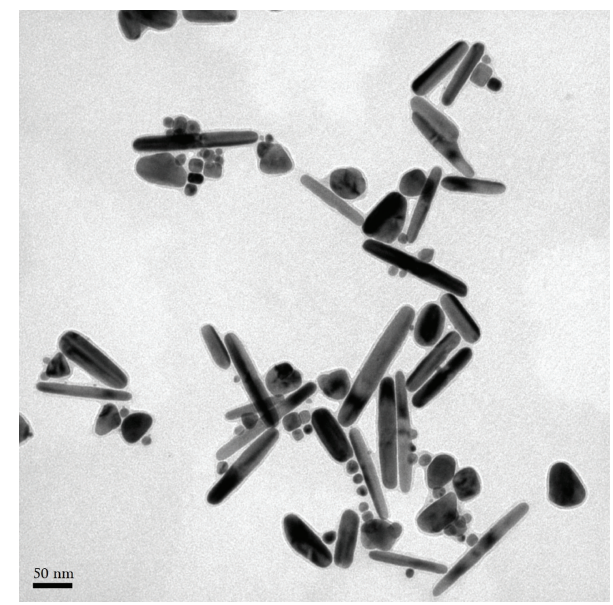

(b)

Figure 3: (a, b) Typical TEM images of Pd-Cu nanorods with different magnifications. The inset in (a) is the corresponding EDS spectrum. 


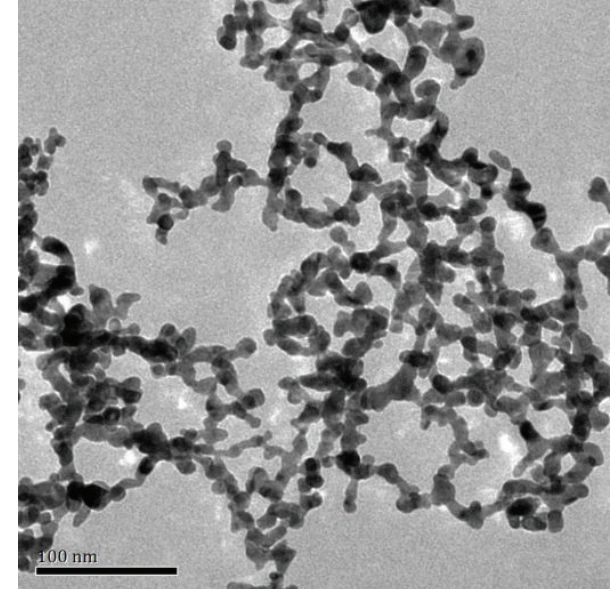

(a)

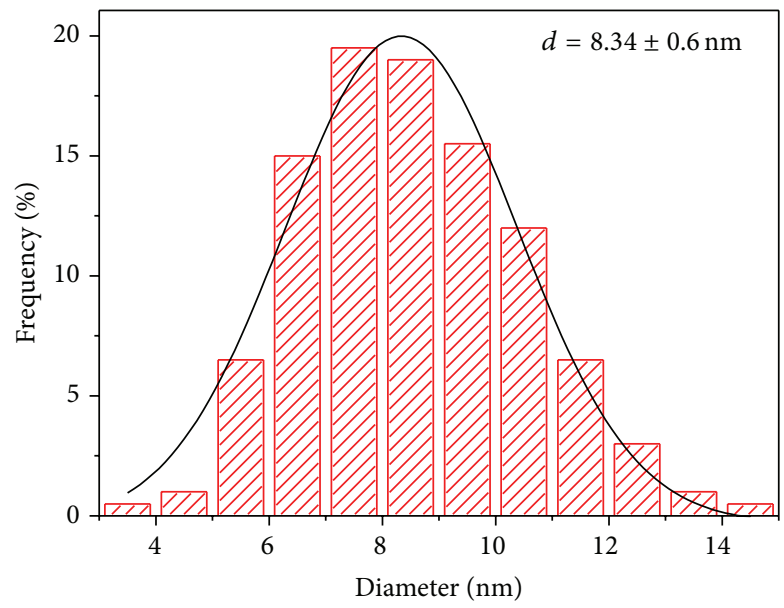

(c)

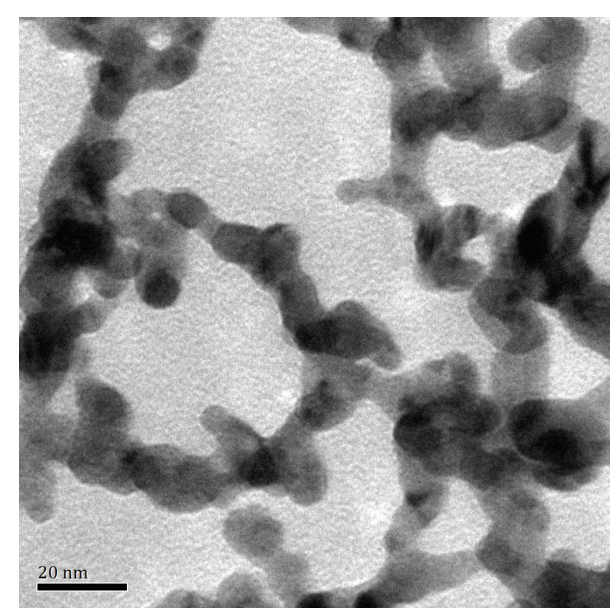

(b)

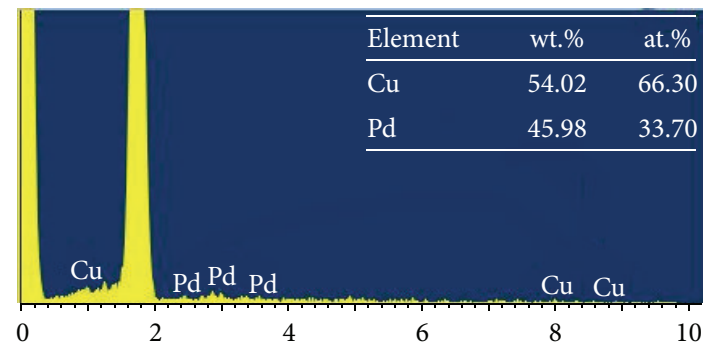

(d)

Figure 4: (a, b) Typical TEM images of Pd-Cu nanowire networks with different magnifications. (c) Particle size distribution analysis. (d) EDS spectrum of the corresponding alloys.

display the highest specific activity among these catalysts. The peak current density of ethanol electrooxidation in the positive potential scan of Pd-Cu near-spherical NPs is approximately $11.7 \mathrm{~mA} / \mathrm{cm}^{2}$, which is nearly 5.5 times higher than that $\left(2.1 \mathrm{~mA} / \mathrm{cm}^{2}\right)$ of the commercial $\mathrm{Pd} / \mathrm{C}$. It is well known that the noble metal catalyst such as Pd usually shows superior activity at edges and corners $[13,18]$. In this case, the synthesis of Pd-based nanoparticles with edges/frame structure is extremely desired. Meanwhile, here in our experiments, the highest activity for Pd-Cu near-spherical NPs with edges truncation is in good agreement with this [18].

To further evaluate the stability on ethanol electrooxidation of Pd-Cu alloy catalysts and commercial Pd/C catalyst, we recorded CA curves for $600 \mathrm{~s}$ at $-0.25 \mathrm{~V}$ (versus SCE) in the solution of $0.5 \mathrm{M} \mathrm{KOH}$ containing $1.0 \mathrm{M}$ ethanol (shown in Figure 7(b)). CA curves indicate that the Pd-Cu nearspherical NPs possess the higher stability for the entire time course, which further verifies that Pd-Cu near-spherical NPs exhibit better electrocatalytic performance in the EOR.

\section{Conclusions}

In this study, a simplified one-pot synthetic strategy has been developed to prepare $\mathrm{Pd}-\mathrm{Cu}$ alloys with various morphologies from near-spherical to nanorods and nanowire networks structures. The use of KOH/EG with different concentration was demonstrated to play a critical role in the shape evolution of $\mathrm{Pd}-\mathrm{Cu}$ alloys. Among these alloys, the near-spherical $\mathrm{Pd}-\mathrm{Cu}$ catalyst shows the highest specific activity and stability toward the electrooxidation of ethanol in comparison with commercial $\mathrm{Pd} / \mathrm{C}$ catalyst, mainly due to the advantages of more edge truncation, a greater number of active sites, and bimetallic synergistic effects. Having the excellent electrocatalytic activity, optimal stability, and cost effectiveness, the near-spherical Pd-Cu NPs exhibit great potential as an efficient anode catalyst for DEFCs.

\section{Conflict of Interests}

The authors declare that there is no conflict of interests regarding the publication of this paper. 


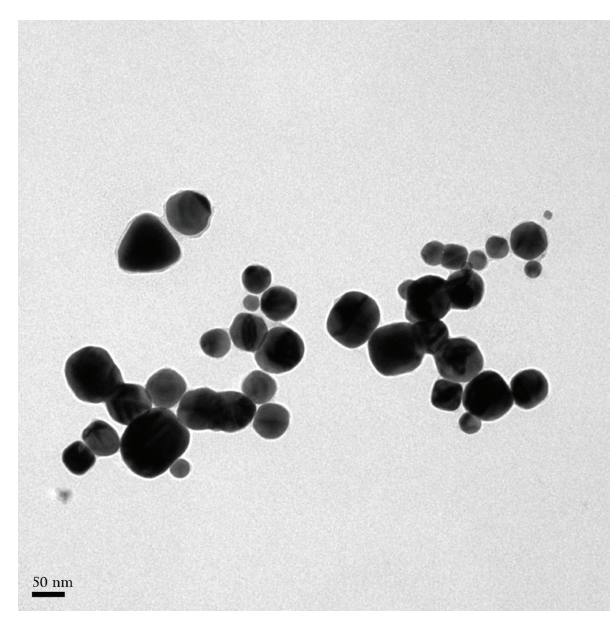

(a)

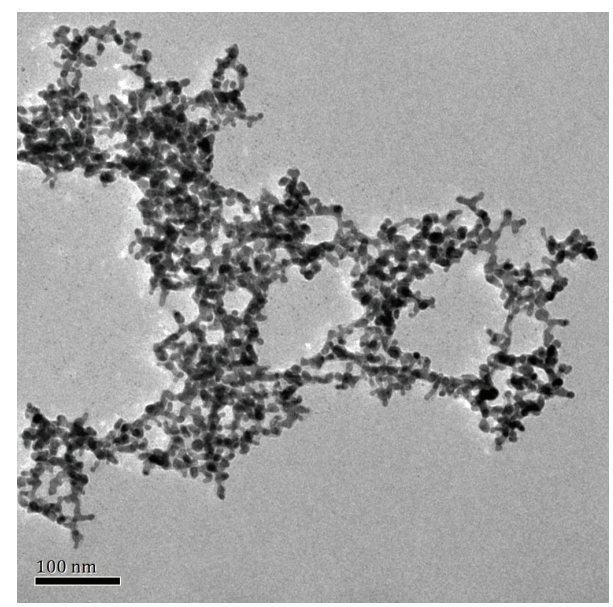

(c)

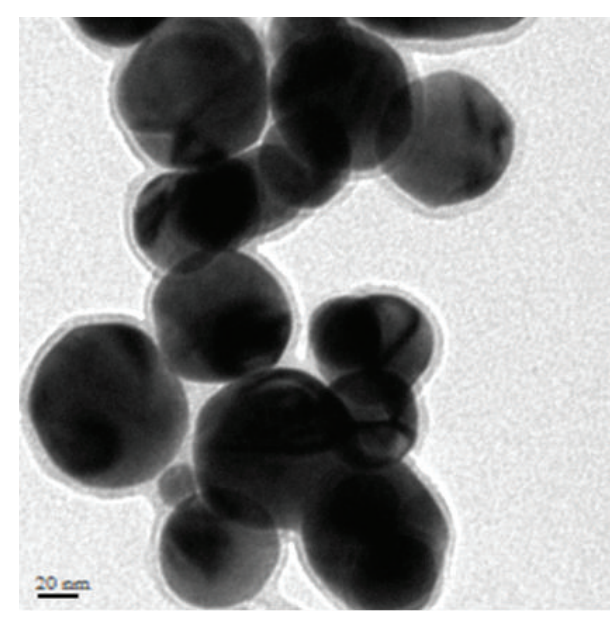

(b)

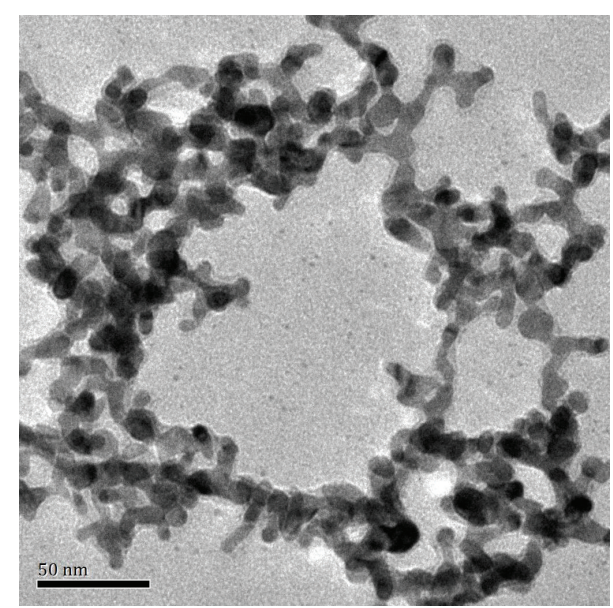

(d)

FIGURE 5: Typical TEM images of Pd-Cu alloys with different magnifications collected under the same conditions, except the variation in the concentration of KOH/EG: (a, b) $0.1 \mathrm{mM}$ and (c, d) $1 \mathrm{M}$.

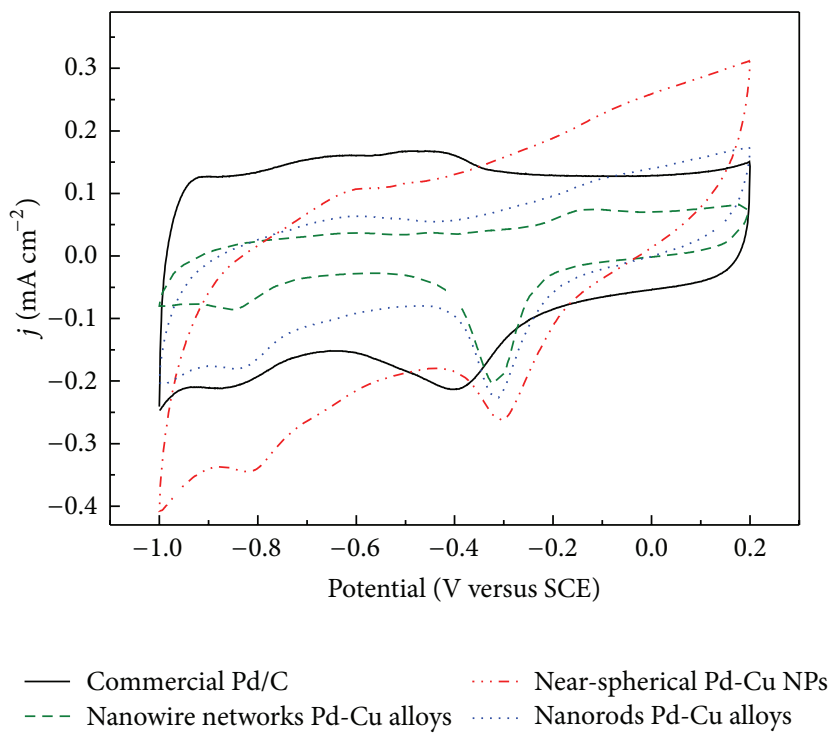

Figure 6: CV curves of modified electrodes for commercial Pd/C, near-spherical Pd-Cu NPs, nanorods Pd-Cu alloys, and nanowire networks $\mathrm{Pd}-\mathrm{Cu}$ alloys in $0.5 \mathrm{M} \mathrm{KOH}$ at a scan rate of $50 \mathrm{mV} \mathrm{s}^{-1}$. 


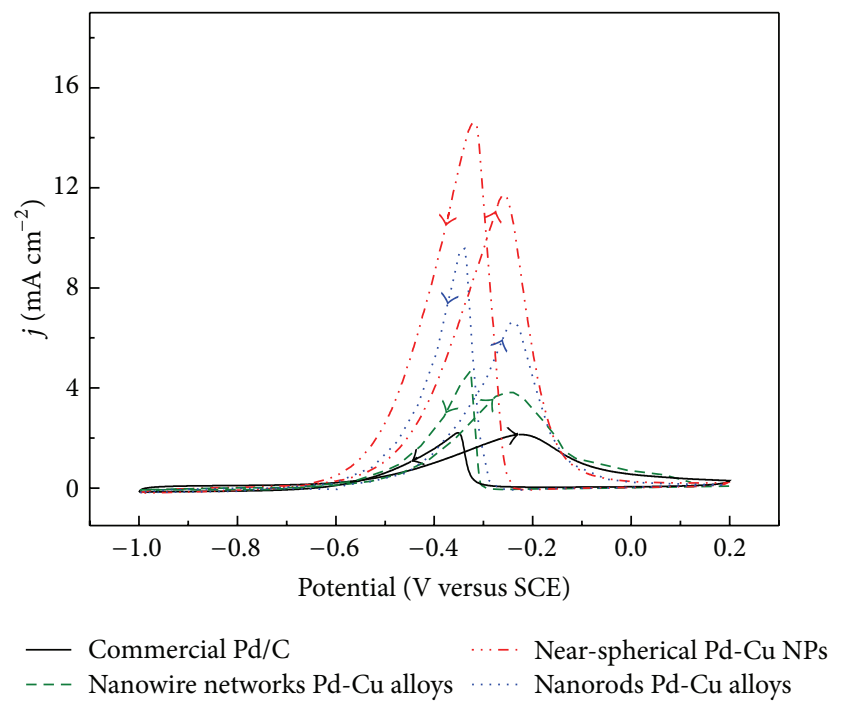

(a)

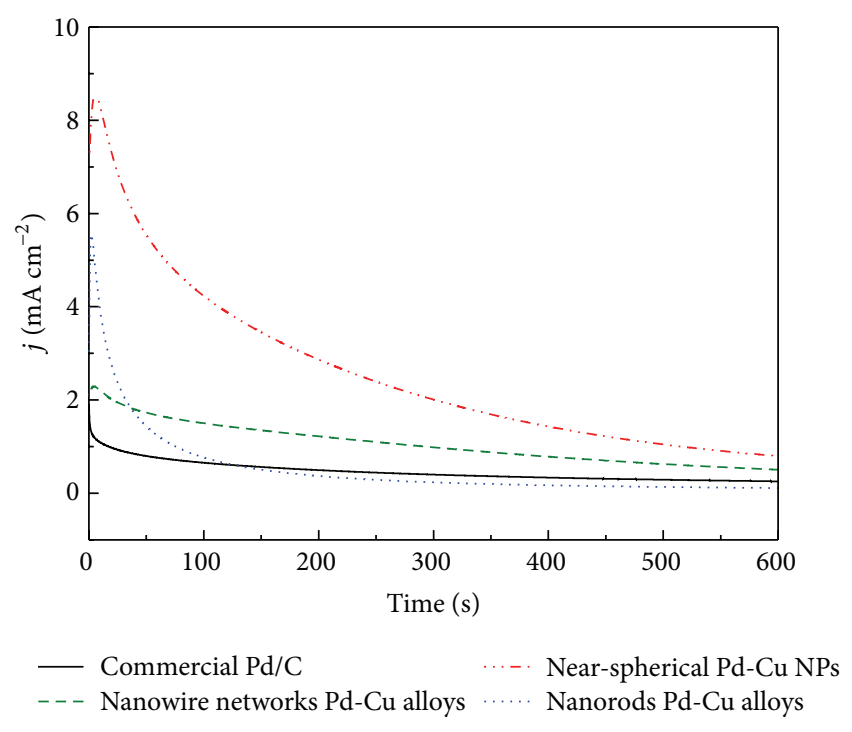

(b)

Figure 7: (a) CV curves and (b) CA curves (at -0.25 V versus SCE) of modified electrodes for commercial Pd/C, near-spherical Pd-Cu NPs, nanorods Pd-Cu alloys, and nanowire networks Pd-Cu alloys in $0.5 \mathrm{M} \mathrm{KOH}$ containing $1.0 \mathrm{M}$ ethanol at a scan rate of $50 \mathrm{mV} \mathrm{s}$.

\section{Acknowledgment}

This work was supported by National Natural Science Foundation of China (Approval nos. 21103055 and 21473063).

\section{References}

[1] L. Carrette, K. A. Friedrich, and U. Stimming, "Fuel cells: principles, types, fuels, and applications," ChemPhysChem, vol. 1, no. 4, pp. 162-193, 2000.

[2] U. B. Demirci, "Direct liquid-feed fuel cells: thermodynamic and environmental concerns," Journal of Power Sources, vol. 169, no. 2, pp. 239-246, 2007.

[3] Q. Dong, Y. Zhao, X. Han, Y. Wang, M. C. Liu, and Y. Li, "Pd/Cu bimetallic nanoparticles supported on graphene nanosheets: facile synthesis and application as novel electrocatalyst for ethanol oxidation in alkaline media," International Journal of Hydrogen Energy, vol. 39, no. 27, pp. 14669-14679, 2014.

[4] Q. H. Zhang, W. H. Yang, H. H. Wang, M. Q. Wang, and C. J. Cai, "Facile synthesis of Platinum alloy nanoparticles with enhanced activity for ethylene glycol electro-oxidation," ECS Electrochemistry Letters, vol. 3, no. 12, pp. F73-F75, 2014.

[5] B. Wu, Y. J. Kuang, X. H. Zhang, and J. H. Chen, "Noble metal nanoparticles/carbon nanotubes nanohybrids: synthesis and applications," Nano Today, vol. 6, no. 1, pp. 75-90, 2011.

[6] M. Rezaei, S. H. Tabaian, and D. F. Haghshenas, "Electrochemical nucleation and growth of Pd/PdCo core-shell nanoparticles with enhanced activity and durability as fuel cell catalyst," Journal of Materials Chemistry A, vol. 2, no. 13, pp. 4588-4597, 2014.

[7] J.-J. Lv, S.-S. Li, A.-J. Wang et al., "One-pot synthesis of monodisperse palladium-copper nanocrystals supported on reduced graphene oxide nanosheets with improved catalytic activity and methanol tolerance for oxygen reduction reaction," Journal of Power Sources, vol. 269, pp. 104-110, 2014.
[8] C. Z. Zhu, S. J. Guo, and S. J. Dong, "Rapid, general synthesis of PdPt bimetallic alloy nanosponges and their enhanced catalytic performance for ethanol/methanol electrooxidation in an alkaline medium," Chemistry-A European Journal, vol. 19, no. 3, pp. 1104-1111, 2013.

[9] Q. Gao, Y.-M. Ju, D. An et al., "Shape-controlled synthesis of monodisperse $\mathrm{PdCu}$ nanocubes and their electrocatalytic properties," ChemSusChem, vol. 6, no. 10, pp. 1878-1882, 2013.

[10] M. M. Liu, Y. Z. Lu, and W. Chen, "PdAg nanorings supported on graphene nanosheets: highly methanol-tolerant cathode electrocatalyst for alkaline fuel cells," Advanced Functional Materials, vol. 23, no. 10, pp. 1289-1296, 2013.

[11] P. Mukherjee, P. S. Roy, K. Mandal, D. Bhattacharjee, S. Dasgupta, and S. K. Bhattacharya, "Improved catalysis of room temperature synthesized $\mathrm{Pd}-\mathrm{Cu}$ alloy nanoparticles for anodic oxidation of ethanol in alkaline media," Electrochimica Acta, vol. 154, pp. 447-455, 2015.

[12] T. Maiyalagan, X. Wang, and A. Manthiram, "Highly active $\mathrm{Pd}$ and Pd-Au nanoparticles supported on functionalized graphene nanoplatelets for enhanced formic acid oxidation," RSC Advances, vol. 4, no. 8, pp. 4028-4033, 2014.

[13] X. H. Xia, S.-I. Choi, J. A. Herron et al., "Facile synthesis of palladium right bipyramids and their use as seeds for overgrowth and as catalysts for formic acid oxidation," Journal of the American Chemical Society, vol. 135, no. 42, pp. 1570615709, 2013.

[14] W. X. Niu, L. Zhang, and G. B. Xu, "Shape-controlled synthesis of single-crystalline palladium nanocrystals," ACS Nano, vol. 4, no. 4, pp. 1987-1996, 2010.

[15] H. W. Huang, Y. Wang, A. Ruditskiy et al., "Polyol syntheses of palladium decahedra and icosahedra as pure samples by maneuvering the reaction kinetics with additives," ACS Nano, vol. 8, no. 7, pp. 7041-7050, 2014.

[16] Z.-Y. Shih, C.-W. Wang, G. Xu, and H.-T. Chang, "Porous palladium copper nanoparticles for the electrocatalytic oxidation of methanol in direct methanol fuel cells," Journal of Materials Chemistry A, vol. 1, no. 15, pp. 4773-4778, 2013. 
[17] L. Zhang, S.-I. Choi, J. Tao et al., "Pd-Cu bimetallic tripods: a mechanistic understanding of the synthesis and their enhanced electrocatalytic activity for formic acid oxidation," Advanced Functional Materials, vol. 24, no. 47, pp. 7520-7529, 2014.

[18] Z. C. Zhang, Y. Yang, F. Nosheen et al., "Fine tuning of the structure of $\mathrm{Pt}-\mathrm{Cu}$ alloy nanocrystals by glycine-mediated sequential reduction kinetics," Small, vol. 9, no. 18, pp. 30633069, 2013.

[19] S. T. Nguyen, H. M. Law, H. T. Nguyen et al., "Enhancement effect of $\mathrm{Ag}$ for Pd/C towards the ethanol electro-oxidation in alkaline media," Applied Catalysis B: Environmental, vol. 91, no. 1-2, pp. 507-515, 2009. 

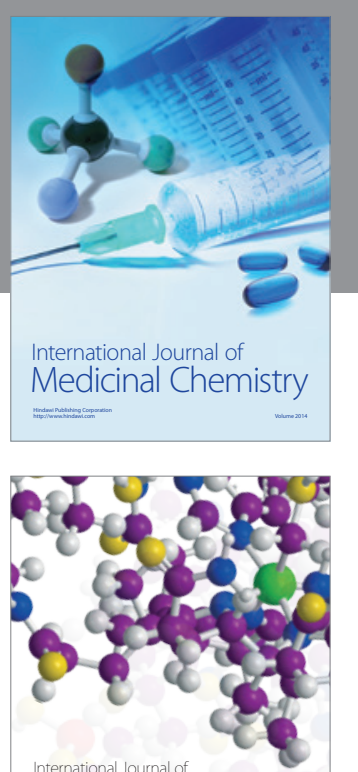

Carbohydrate Chemistry

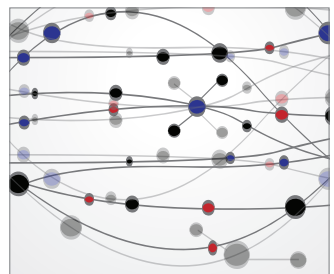

The Scientific World Journal
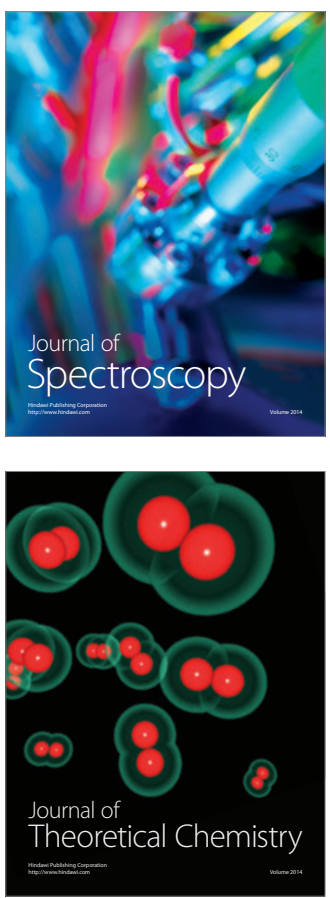
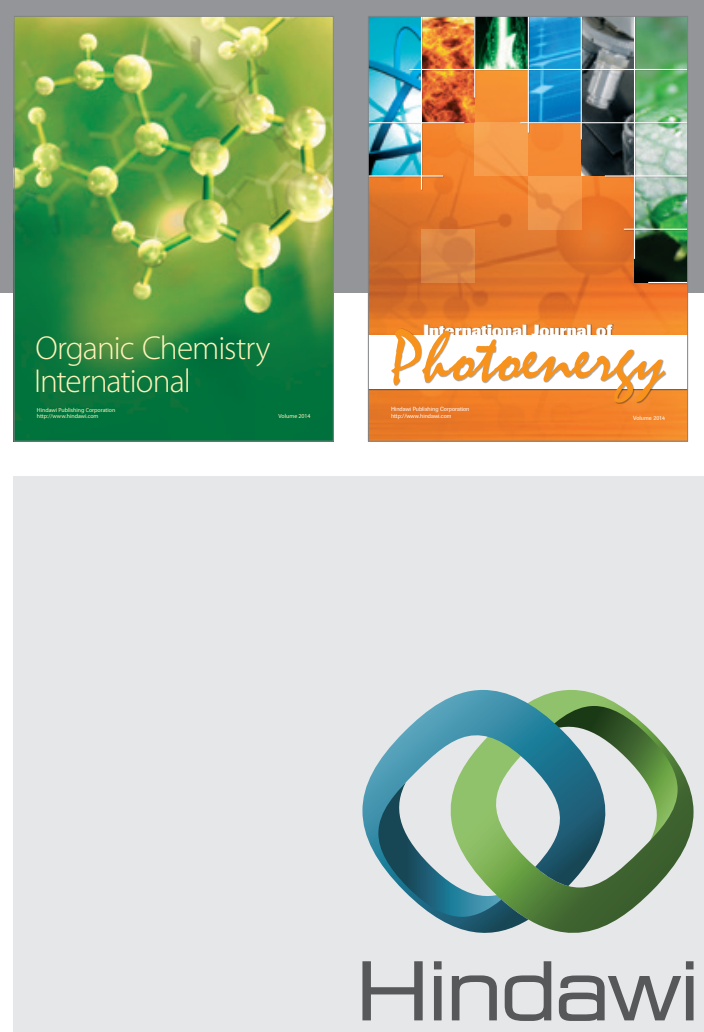

Submit your manuscripts at

http://www.hindawi.com

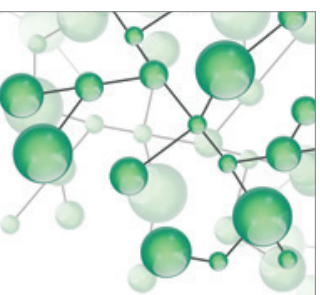

International Journal of

Inorganic Chemistry

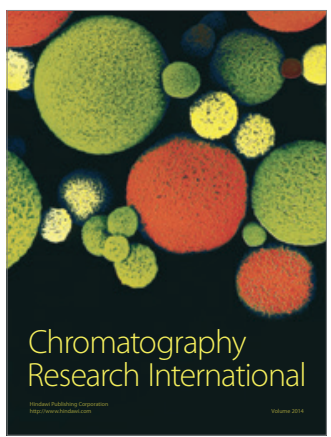

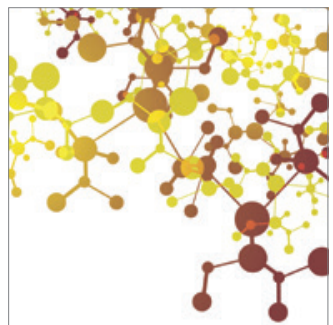

Applied Chemistry
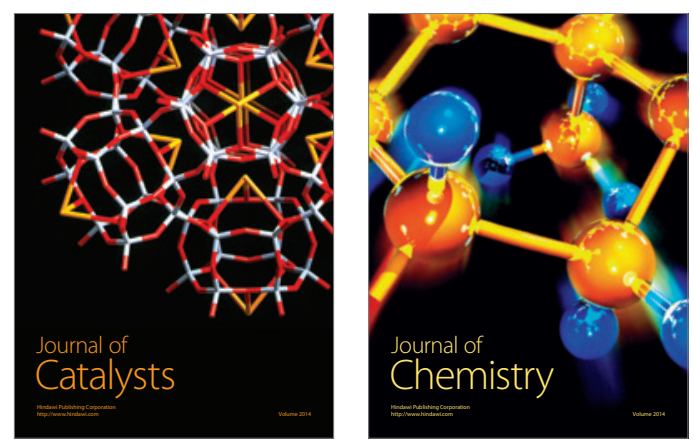
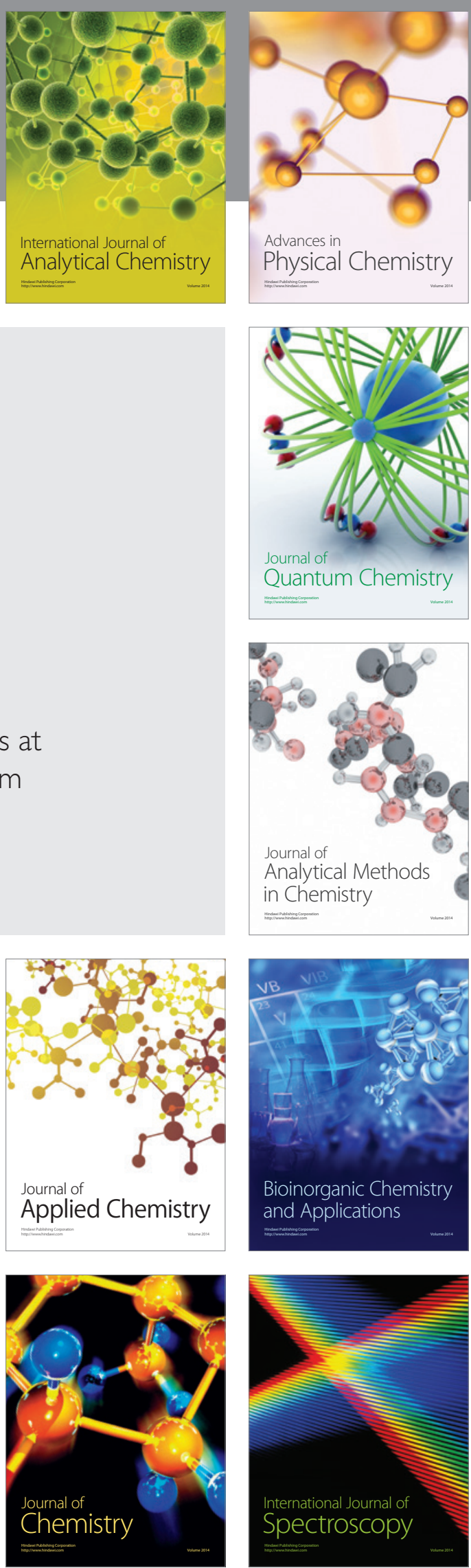